\title{
The Formation of the Sexual Nuclei in Lilium Martagon:
}

\author{
II. Spermatogenesis.
}

BY

ETHEL SARGANT.

With Plates $\mathbf{X}$ and $\mathbf{X I}$.

T $\mathrm{N}$ the first part of this paper I described the three nuclear divisions which take place within the embryo-sac of Lilium Martagon and form the nucleus of the ovum there. The reasons which led me to undertake a fresh examination of material rendered classical by previous research will be found at the beginning of that part. My object was to examine each of those three nuclear generations with the single aim of determining whether there was ground for the belief that any one of the nuclei in that series was formed of chromosomes derived from those of the previous generation by transverse fission. Dr. Haecker's hypothesis, which I have discussed elsewhere (I, pp. $445^{-9}{ }^{1}$ ), demands that one of the three nuclei in question should be so formed ${ }^{2}$. It further demands that in the parallel series of four nuclear generations which terminates in the formation of the male pronucleus

1 This and all similar references are to Part I of this paper, Annals of Botany, $\mathrm{x}, \mathrm{I} 896$.

2 Dr. V. Haecker, The Reduction of the Chromosomes in the Sexual Cells as described by Botanists, Annals of Botany, ix, 1895 .

[Annals of Botany, Vol. XI. No. XLII. June, 1807.] 


\section{Sargant.-Formation of the Sexuai Nuclei}

within the pollen-tube, a similar transverse fission of chromosomes should occur.

My observations on the oögenesis of Lilium Martagon give no support to this view. They confirm the conclusion of all previous observers in showing that the chromosomes of each generation are formed by longitudinal fission from the parent chromosomes. I have now concluded a corresponding set of observations on the spermatogenesis of the same plant. Here again we have a series of nuclear generations to be examined so closely that, if a transverse fission of chromosomes should really take place in any one of them, the signs of it may not escape observation.

So minute an inquiry into the details of karyokinesis as that required for this purpose cannot fail to furnish evidence on such general questions as the relation between nucleus and cytoplasm, the function of the nucleolus, and so forth. But one general result obtained from comparison of the spermatogenetic with the oögenetic series requires special mention. The first karyokinesis of either series differs in so many details from those which succeed it, that it may be said to present a different type of nuclear division. Professor Farmer has already pointed out the difference between the first and second nuclear divisions in the pollenmother-cell of Lilium, applying to them the zoological terms heterotype and homotype ${ }^{1}$. How far this nomenclature is justified from a zoological standpoint, I am not competent to determine. But, using the words strictly in the sense suggested by their etymology, they seem to me peculiarly applicable to the case of Lilium Martagon. The second and third divisions of the micropylar nuclei in the embryo-sac of that plant follow the vegetative type of karyokinesis (I, p. 468). This is quite evident when Figs. 30 and 42 in Part I are compared with Fig. 6. The nuclear divisions

1 J. B. Farmer, Ueber Kerntheilung in Lilium-Antheren, \&c., Flora, 1895 , Heft I. See also Farmer and Moore, On the essential Similarities existing between the heterotype nuclear Divisions in Animals and Plants, Anatomischer Anzeiger, xi, I895, Heft 3 . 
in question differ from a vegetative division in the number of chromosomes, and in no other respect. They may properly be called homotype. The same term is equally applicable to the three later divisions of the spermatogenetic series.

The first division of the pollen-mother-cell nucleus in Lilium Martagon is similar in every detail to that of the primary embryo-sac nucleus. Both divisions exhibit a type of karyokinesis differing very widely from that of vegetative nuclei. The difference is sufficiently great to justify the use of the term heterotype.

In a communication at a recent meeting of the British Association (Liverpool, I8g6), I attempted to define the difference between these forms of karyokinesis in the particular case of Lilium Martagon ${ }^{1}$. My observations on its spermatogenesis were not then completed, and only three out of the four nuclear divisions from that series were described. Now that the details of all the critical nuclear divisions on either side have been published, we have the materials for a detailed comparison of the two types in this one instance. Such a comparison may be of value as a basis for future generalisation, for the terms heterotype and homotype have only lately been adopted by botanists. They have a definite meaning, and it is time that their use should be sanctioned if the zoological analogy can be maintained, or that equivalent terms should be found if such analogy is misleading. The first step to this end is that the botanical meaning of the words should be clearly defined.

Little need be said as to the fixing and staining methods which have been applied to the anther. In the main they resemble those which were found suitable to the ovule (I, p. 450, and Appendix). I have maintained the practice of arranging the preparations in two parallel series, one prepared from material fixed in absolute alcohol, the other from material fixed in one of the osmic acid mixtures. As the tissues of the anther are more easily penetrated than those of the ovule, it has been possible to make greater use of

1 Report of the British Association, I896, p. 1021. 


\section{Sargant.-Formation of the Sexual Nuclei}

aqueous fixing-solutions. Details of these processes are given in the Appendix at the end.

Hand-sections have proved of great value for purposes of comparison with thin serial sections in the study of the first division of the pollen-mother-cell nucleus, but they have not been used to illustrate the two following divisions. The history of the fourth nuclear division in this series-that which takes place in the pollen-tube-has been worked out almost entirely by means of hand-sections from alcoholmaterial. This is the only part of the work in which a single fixing method has been used to the exclusion of any other.

\section{Formation of the Nucleus of the Pollen-grais.}

The anther of Lilium Martagon differs from the ovule in possessing a definite archesporial tissue. This grows rapidly by repeated cell-division from the time of its first formation until the pollen-mother-cells are formed. Cell-division then ceases in the loculi for some time, during which the nuclei of the pollen-mother-cells pass through a period of growth and development which corresponds in every detail to that following on the differentiation of the embryo-sac nucleus.

The nuclear divisions in the archesporial tissue are precisely similar to the vegetative divisions described in the first part of this paper (I, p. 45I). The chromosomes are somewhat crowded on a small spindle, and it is therefore difficult to find examples in which they can be counted with certainty, but there are always about twenty-four. We may conclude that when the pollen-mother-cell is differentiated, its nucleus is built up of twenty-four chromosomes.

In an ordinary flower-head of Lilium Martagon, in which ten or twelve buds are still sessile and crowded together at the top of the flower-stalk, anthers from the youngest buds will usually show archesporial tissue in which there is no lack of nuclear divisions. I possess a series of preparations from ten buds of such an inflorescence. The whole flowerhead originally consisted of twelve buds, two of which were 
accidentally destroyed during the process of preparation. The lowest buds in the head were shortly stalked, and stood somewhat apart from the others. The outer perianth-leaves of each bud were broken off, and the rest of it was cut into a series of transverse sections in which all the parts are shown in their proper position. Archesporial nuclear divisions are frequent in the anthers of the two youngest buds. In the third the pollen-mother-cells are differentiated, and the first indication of an embryo-sac can be seen in the median ovules (I, p. 449). Sections from the lower buds show every stage in the history of the pollen-mother-cell nucleus, from its first formation to the differentiation of the spirem-ribbon within it.

Such a series of preparations serves two purposes. It may be considered as a sort of index to the nuclear stages included within it, giving direct evidence as to their seriation; and if we have any means of determining the difference of age between buds at the beginning and those at the end of the series, we know at once about how long the nuclei of any particular tissue in those buds have taken to pass from one stage to another. I should suppose that such a bud as the third in our series would take a week or ten days to attain the size of the lowest bud, and this must also be the time taken by the pollen-mother-cell nuclei to develop from the resting to the spirem-stage.

The whole interval between the complete differentiation of the pollen-mother-cell and the formation of the young pollen-grains within it may conveniently be divided into four periods.

I. The nucleus of the pollen-mother-cell grows larger and aiters in structure, finally assuming the well-known spiremcondition (Figs. $1-3 a$ ).

2. Twelve chromosomes are formed from the spirem-ribbon, and lie loose in the nuclear cavity (Figs. 4-10).

3. The first karyokinesis of the pollen-mother-cell nucleus separates the two halves of each chromosome. Cell-division follows this nuclear division (Figs. $10 a-15$ ). 


\section{I92 Sargant.-Formation of the Sexual Nuclei}

4. The second karyokinesis divides the nucleus of each daughter-cell into two, and is followed by a corresponding cell-division (Figs. 16-22).

Measurements of the pollen-mother-cell nuclei in the earliest stage show that they are then about the same size as the embryo-sac nucleus when just formed. They remain, however, for a much shorter time in the resting-state, and during that period do not increase so much in size. The embryo-sac nucleus is in the resting-state for about a fortnight, and during that time its mean diameter is nearly doubled (I, p. 455, and Figs. IO, II). The nuclei of the pollen-mothercells, on the other hand, do not retain the structure of a restingnucleus for more than a day or two, and their mean diameter increases during that time by less than half its length. Indeed, the pollen-mother-cell nucleus is throughout its development smaller than the embryo-sac nucleus at corresponding stages. No doubt this is connected with the small size of the pollenmother-cell as compared with the embryo-sac. I have drawn the pollen-mother-cells of the figures numbered I, 2, 3-I 5 on the same scale as Figs. 10-26 in Part I for purposes of comparison. When this scale has proved too small to show the necessary detail, portions of nuclei at corresponding stages have been drawn under a higher magnification (Figs. $1 a$, $2 a, \& \mathrm{c}$.).

The structure of the resting pollen-mother-cell nucleus corresponds exactly to that of the resting embryo-sac nucleus, though the detail is not quite so clear. A network of threads which seem to anastomose is partly obscured by the cloudy substance staining like dilute chromatin, which I have called amorphous chromatin. Here and there, in very deeply stained preparations, it can be seen that the threads are dotted $(x$ in Fig. I $a$ ), but this is less clear than in the embryo-sac nucleus. There are usually several spherical nucleoli (Fig. I).

As the nucleus increases in size, the amorphous chromatin is seen to be less generally distributed over the nuclear section. It is aggregated round the threads of the chromatic network, and seems to have diminished in bulk. Some con- 
in Lilium Martagon: II. Spermatogenesis. I93

siderable quantity of amorphous chromatin is still present when the nuclei have completed their growth in size, and even when indications begin to appear of the approach of synapsis.

The passage from the resting-state to the contracted condition known as synapsis is very instructive in these nuclei. No independent evidence of the seriation of stages could be obtained from preparations of the corresponding period in the embryo-sac. The comparative ages of the nuclei, where the difference was slight, were settled on internal evidence only. But in a single longitudinal section from a young anther, the pollen-mother-cell nuclei at one end may be in the late resting-condition, while those at the other are completely contracted. The intermediate nuclei then exhibit an orderly series of transitional forms.

The approach of synapsis is first indicated by the appearance of drops of nucleolar matter adhering to the chromatic network. The larger of these drops can be identified by their reddish colour in sections from alcohol-material stained with methyl-green and acid fuchsin. The nucleoli are still spherical and well defined, but often vacuolated. A little later the nucleoli lose their well-defined outline, the nuclear membrane becomes indistinct, and the chromatic threads show a tendency to collect round the nucleoli at one side of the nuclear cavity (Fig. 2). This contraction becomes more and more pronounced, the nucleoli collect into a shapeless mass of ill-marked outline, and the nuclear membrane seems to have disappeared as a continuous structure. Its place is taken by a sort of web of cytoplasmic fibrils. In sections stained with methyl-green and acid fuchsin it is to be remarked that the nucleolar mass is often coloured green in the thicker parts-as, for example, near $x$ in Fig. 2. Possibly it has dissolved the amorphous chromatin which was still visible in the later stages of the resting-nucleus. The edges of this greenish mass are always of a washy-red colour, and the nuclear sap in its neighbourhood is clouded with red.

Even in such a preparation as that from which Fig. 2 is 


\section{I94 Sargant.-Formation of the Sexuai Nuclei}

drawn, it can be seen that the chromatic threads have grown in thickness. Sections from material fixed in Flemming's solution show the structure of the thread in detail. It is irregularly thickened: here and there drops of nucleolar matter adhere to it $(n, n$, in Fig. $2 a)$. In the broader bits of thread from very clearly stained preparations, a double row of dots can sometimes be made out.

The nucleus of the pollen-mother-cell has now entered on the period of contraction called synapsis, which precedes the formation of the spirem-thread. It is a condition which persists for several days, and the phenomena which distinguish it are familiar to all who have worked at the subject; but it has been considered by most observers to be an artificial state produced by the action of reagents. This is not the place in which to enter into an account of the controversy which has arisen on various points connected with this subject. I shall simply describe my own observations on this period in the history of the pollen-mother-cell in the single case of Lilium Martagon. A fuller account of the evidence will be given than would be necessary if no controversy existed.

The appearance of the nucleus in the contracted state depends very much upon the thickness of the section examined. If it is thick enough to include the whole depth of most of the nuclei contained in it, the general appearance of each is that shown in Fig. 3, which is drawn from a handsection of alcohol-material. All that is visible of each nucleus in such a section is a swollen nuclear cavity containing a ball of chromatic substance, which adheres to one side of it. The ball is clearly formed of close coils; some of them can be distinguished from each other near the edge of the ball. No definite nuclear membrane can be made out; but this is not conclusive in such a preparation, for its thickness necessarily renders details indistinct.

Before proceeding to a description of thin serial sections, which give details of the nuclear structure in this stage with great precision, I will give a complete account of those observations on living material which have been mentioned 
already (I, p. 45I). It is clear that such observations are of importance, for if well established they will settle the question as to the natural or artificial character of the contraction we are dealing with.

It has already been said that the nuclei of the pollenmother-cells remain in the contracted condition for several days. It is therefore easy to find material of the right age. Anthers are chosen from buds which stand midway between the highest and lowest buds of such an inflorescence as that described on page 190. The only difficulty in their preparation lies in cutting sufficiently thin sections from fresh material. This can generally be done in elder-pith with a dry razor. The sections were mounted in sap expressed from the perianth-leaves of the bud, and were covered with a glass slip. They were examined with a homogeneous immersion objective of $2 \mathrm{~mm}$. focal length, N.A. I.3O, from Zeiss' apochromatic series; eye-pieces 4 and 6 were used. The Powell and Lealand condenser was lowered until the angle of the incident light-from an incandescent gas-burner-was sufficiently narrow to give a clear outline to the unstained nucleus ${ }^{1}$.

Notes were taken of the observations made in this way on three separate occasions, and outline drawings of the pollenmother-cell and its nucleus were kept. Within the rather obscure wall of the pollen-mother-cell was seen a clear space, well outlined against the granular protoplasm filling the rest of the cell. One side of this space was occupied by a rather opaque spherical ball.

It now became necessary to identify the features of this outline. On two mornings the section was roughly fixed and stained by Strasburger's well-known method of allowing methyl-green dissolved in one per cent. acetic acid to run in under the cover-slip. This very imperfect fixing method produced deformation in the shape of the clear space, but the

1 This is the arrangement of optical conditions which I have found to give the best results. When the aperture of the incident light was decreased by the use of an iris diaphragm, the definition of the image was less perfect than that obtained by lowering the condenser. 


\section{I96 Sargant.-Formation of the Sexual Nuclei}

spherical ball stained an intense green, and thus showed the presence of chromatin. The section cut on the third morning was particularly successful, and was preserved for future reference by laying it in much diluted Merkel's solution for half an hour, and then staining with Mayer's haemalum. I could not detect any alteration in the shape of the nuclei after this fixing and staining process. The fixed and stained section, though thin for one cut from fresh material, cannot be compared with a good hand-section from a hardened anther, and the structure of the nuclei is further obscured by the heavy stain; but there can be no doubt that the nuclei are really in the condition of synapsis. Their outlines correspond perfectly well with that drawn from a nucleus in the fresh section before fixing.

We may now proceed to examine the structure of the contracted nucleus in detail by means of sections considerably thinner than its mean diameter. The appearance of any particular nucleus in such a section will depend greatly upon how the contracted part lies with reference to the plane of the section. If the knife has passed through the area over which the chromatic ball is in contact with the boundary of the nuclear cavity, then the section of the nucleus will have an outline resembling that of Fig. $3 \alpha$. But if the section is roughly parallel to the area of contact, the chromatic ball may appear as a circular disk within the nuclear cavity, but quite free from it. In this case the whole section of the chromatic ball commonly drops out, leaving the nuclear cavity as an empty space of irregular outline. It often happens also that the sections are injured by the knife, perhaps because the absence of a definite nuclear membrane weakens the structure of the whole nucleus. At any rate, fragments of the chromatic thread and bits of nucleolar matter are constantly found outside the nuclear cavity, and the whole preparation is apt to look ragged and untidy.

Neglecting such details as may be fairly attributed to imperfect preservation, we find that there are three features characteristic of synapsis-a more or less complete disap- 
pearance of the nuclear membrane, partial solution of the nucleolus, and contraction of the chromatic thread. The structure which we have hitherto called the chromatic ball is seen to consist of the chromatic threads closely coiled round a mass of semi-fluid matter, which must be chiefly of nucleolar origin. As we have seen, the colouring in preparations stained with methyl-green and acid fuchsin suggests that there is also some amount of chromatin dissolved in this mass. The chromatic threads in nuclei which have just entered on synapsis-for instance, those at one end of a loculus which shows resting-nuclei at the other end-resemble that drawn in Fig. $2 \alpha$. Such threads are irregularly thickened, and the double row of dots can only be made out here and there. The cytoplasm which surrounds the nucleus often shows fibrillar structure at this time, and in the absence of a proper membrane the nuclear cavity is outlined by a denser web of cytoplasmic fibrils (Fig. 3).

The structure I have just described is characteristic of the earlier period of synapsis. Later on-in such a nucleus, for example, as that drawn in Fig. $3 a$-the nuclear membrane begins to reappear, nucleoli are slowly reconstructed out of the amorphous nucleolar mass, and the coils of the chromatic thread become looser. The thread itself is now of uniform breadth, and is bordered by two regular rows of dots (Fig. $3^{b}$ ). These changes proceed slowly until the chromatic coils occupy nearly the whole of the nuclear cavity, which is once more bounded by a well-marked membrane. The nucleoli are more or less spherical and of definite outline. No trace of an amorphous mass remains. The spirem-stage is reached when the chromatic coils, which can now be seen to form a continuous ribbon, occupy the whole of the nuclear cavity.

The structure of the pollen-mother-cell nucleus in the spirem-condition is perfectly clear. It is a good deal smaller than the embryo-sac nucleus at the corresponding stage (cf. Fig. 4 with Fig. 14 in Part I), and the coils of ribbon are more closely packed in the nuclear cavity. The ribbon itself looks broader than the ribbon of the embryo-sac nucleus; but 


\section{I98 Sargant.-Formation of the Sexual Nuclei}

this is the effect of unconscious comparison between the breadth of the ribbon and the size of the nucleus. Wherever the full breadth of the twisted ribbon can be seen, it turns out to be about the same in both. Sometimes the nucleus has a single nucleolus at this stage (Fig. 4), but commonly there are two or more. The differentiation of the chromatin-granules on the ribbon is perfectly clear even in thick sections from alcohol-material (Fig. 4); thin tangential sections from nuclei fixed in Hermann's solution show it very beautifully, as in the preparation from which Fig. $4 a$ is drawn. This preparation is stained with Flemming's triple stain (I, p. 474 Appendix), in which the characteristic colour of chromatin is a dull purple, and that of nucleolus and cytoplasm orange-red. The matrix of the spirem-ribbon stains red under this treatment, while the granules which border it are dark. Other double stains bring out the same distinction: the ribbon itself stains like the nucleolus and cytoplasm, while the dots take the colour of chromatin.

We have now traced the history of the pollen-mother-cell nucleus through the first period of its development. That period is occupied by the formation of the spirem-ribbon. We have seen that it is differentiated while the nucleus is in the contracted condition known as synapsis, and it seems probable that the linin-matrix of the ribbon is formed in great part from the substance of the half-dissolved nucleolus. The double row of chromatin-granules can be first demonstrated with certainty during the condition of synapsis, but there is reason to think that it was formed by the fission of the pre-existing single row before the final contraction took place. In all these points, as also in minor details, the development of the pollen-mother-cell nucleus agrees exactly with that of the embryo-sac nucleus.

The nucleus of the pollen-mother-cell remains for a short time in the spirem-condition. When development proceeds again, it still shows the closest agreement with that of the embryo-sac nucleus. As before, however, the smaller size of the former nuclei renders detail less clear. On the other 
hand, we again have evidence as to the seriation of the developmental stages from the position of the mother-cells in the loculus. Moreover, the smaller diameter of the nuclei is of advantage in one way; for though an untouched nucleus is only to be met with in hand-sections, yet serial sections of I $5 \mu$ thickness include more than half the depth of favourably placed nuclei, and such preparations form a valuable link between those which show the complete nucleus, in which details are obscured by the thickness of the section, and the clear but fragmentary preparations of nuclei found in serial sections of thickness varying from $5 \mu$ to $10 \mu$.

As in the embryo-sac nucleus, longitudinal fission is found in parts of the spirem-ribbon before it has been divided into lengths by transverse division $\left(x \text { and } x^{\prime}, \text { Fig. } 5\right)^{1}$. Articulation or beading of the spirem-ribbon precedes the formation of these loops. Short segments of the ribbon, including two or more pairs of granules, become slightly swollen, and the ribbon between such segments is rather narrower than in other places (Fig. 4a). In the preparation from which Fig. 5 is drawn, indications are already seen of the approaching solution of the nucleolus : the nuclear sap is coloured cloudily in places. Thus at $x$ the space between the two rows of granules is slightly coloured as compared with the surrounding space, but this only occurs in the neighbourhood of the nucleolus. At $\times$, for example, the space within the loop is quite clear. Details of the process of longitudinal fission are seen in such tangential sections of nuclei as that shown in Fig. $5 a$, which is from the same anther as the nucleus drawn in Fig. $4 a$.

The separation of the two rows of granules is nearly if not quite complete when the spirem-ribbon first shows indications of a division into lengths. Fig. 6, for example, is drawn from a nucleus near that from which Fig. 5 is taken; at $\times$ a transverse division has just taken place, and when the section is narrowly examined, longitudinal fission can be made out in the ribbon wherever the nuclear sap is uncoloured. Solution of the nucleolus $(n)$ has clearly begun, and the

\footnotetext{
1 J. B. Farmer, Journal of the Royal Microscopical Soc., Oct. 1895, p. $5^{\circ 2}$.
} 


\section{Sargant.-Formation of the Sexual Nuclei}

coloured nuclear sap seems to run in between the two rows of granules like a soap-film between knitting needles. Thus the space between such rows is often more highly coloured than the surrounding region, as may be seen to the right of Fig. 6 . In that part of the nuclear section it almost seems as if fission of the ribbon had not taken place, or was incomplete; but on the left of the figure the sap is clear, and no mistake is possible.

Division of the spirem-ribbon has now taken place in two directions. The rows of chromatin-granules which border it have been separated from each other by longitudinal fission, and the double thread thus formed has been transversely divided into lengths. These lengths, each consisting of two dotted filaments much twisted on each other, are in fact immature chromosomes, and when they have assumed a more compact shape, we shall find that there are twelve of them.

The development of the mature chromosome from each pair of twisted filaments begins at once, and it is a curious fact that the process is accompanied by all the signs of synapsis. I have already spoken of the gradual solution of the nucleolus. In Figs. 7 and $7 a$ we see an amorphous mass of nucleolar matter which recalls an earlier stage (cf. Fig. $3 a$ ). The twisted threads cluster round this mass at one side of the nuclear cavity, and the nuclear membrane becomes obscure or actually disappears. The contraction itself is clearer at a rather later stage than that shown in Fig. $7 a$, and is never so well marked as in the embryo-sac nucleus (I, Fig. I 8), but its character cannot be mistaken. In examining anther-sections under a low power, I have frequently been unable to decide whether the contracted nuclei at one end of the loculus were younger or older than those in the spirem-stage at the other end. Indeed, it requires fairly high magnification, and some attention, to distinguish between stages of synapsis which are just passing into the spiremcondition and the contracted stages which follow it.

It should be noticed that in the stage represented in Fig. $7 a$, the presence of coloured sap between the dotted filaments is 
very conspicuous. As the nucleus emerges from the contracted state and the nucleoli are reconstituted, this feature disappears. The filaments, which looked ragged when first formed-an appearance easily understood when we remember the lumpy distribution of the linin in the spirem-ribbon during longitudinal fission (Figs. $4 a$ and $5 a$ )-become of uniform thickness during this second synapsis (Fig. 8), and before the end of that period two rows of dots can be made out in each filament. The young chromosome now consists of two lengths of ribbon twisted round each other ${ }^{1}$. Each length bears two rows of dots (Fig. $8 a$ ). These four rows of dots are the product of two successive longitudinal fissions. The ribbons continue to grow in breadth (Fig. 9a), while the nuclear membrane reappears and the nucleolus resumes its definite outline (Fig. 9). No further change in the structure of the chromosome takes place for some time. It continues to grow shorter and broader, and the twist of its two segments on each other becomes closer.

The chromosomes which will take part in the first karyokinesis of the pollen-mother-cell nucleus are now nearly mature. They lie loose within the nuclear membrane in company with the nucleoli (Fig. IO). Each consists of two segments which are already perfectly distinct, and which will be separated from each other in the course of the coming karyokinesis. The chromosomes of a vegetative nucleus show no fission until it is mature and has taken its place on the spindle (I, p. 454 and Fig. 5). But in the pollenmother-cell nucleus we have seen that the fission of chromatingranules took place within the immature spirem-ribbon many days before karyokinesis. The fission thus begun was completed by the splitting of the spirem-ribbon before it

${ }^{1}$ In very deeply stained preparations from material fixed in Flemming's solution, it is seen that some of the young chromosomes are connected with each other by irregular fibrils. These disappear at a later stage. In the same preparations similar fibrils usually connect these chromosomes with the nuclear membrane. I believe the fibrils to be cytoplasmic, and to proceed from the adherence of certain chromosomes to the fibrillar envelope during the absence of the nuclear membrane. 
had been divided into chromosomes. Thus each chromosome has been divided into two segments from the very outset of its independent existence, and these segments were formed by a process of longitudinal fission.

It is a remarkable fact that in such an immature chromosome as that drawn in Fig. 9 a, each segment exhibits a fission of chromatin-granules exactly resembling that which preceded the complete fission of the whole chromosome. We are naturally led to expect that this also will be completed at a later stage of development, and that such a chromosome as we have described has an essentially fourfold structure. This view is the more tempting when we recall the formation of tetrad-groups, which is so characteristic of the animal spermatocyte. Dr. Brauer has shown that in the case of Ascaris each tetrad-group is the result of a double longitudinal fission ${ }^{1}$.

The chromosomes of the pollen-mother-cell nucleus of Lilium Martagon, however, undergo a change, on the final disappearance of the nuclear membrane, which effectually conceals all traces of the incomplete fission just described. $\mathrm{Up}$ to the time of that disappearance the segments of each chromosome show the differentiated structure drawn in Fig. $9 a$. But as the membrane vanishes, the colouring of the chromosome-segments becomes uniform. Each is apparently homogeneous. There is no contrast between cyanophilous granules and erythrophilous ribbon, but the whole chromosome stains uniformly like chromatin (Fig. II). A similar change has been observed at the corresponding period in the history of the embryo-sac nucleus (I, p. 46I).

The true structure of the mature chromosome is very much obscured by this change in colouring power. However tightly its segments were twisted on each other, they could still be distinguished without difficulty so long as each consisted of a ribbon outlined with a dark border of dots. Now, however, the segments are indistinguishable where they cross each other. The loops between them are sometimes fairly large,

1 Brauer, Zur Kenntniss der Spermatogenese von Ascaris megalocephala, Arch. f. mikr. Anat., V. 42, I 893 . 
and in such cases the twist of the segments on each other can be made out (Figs. I I and I $a$ ). When the twist is tight, the loops may appear as circular dots in the otherwise seemingly solid chromosome, or no loops at all may be visible. This is particularly apt to occur in preparations from material fixed with absolute alcohol. The real structure may be demonstrated in such cases-at the cost of the preparation-by first treating the nucleus with warm $50 \%$ acetic acid to clear the structure ${ }^{1}$, and then allowing fuming hydrochloric acid to run in under the cover-slip ${ }^{2}$. The cellulose and cytoplasmic structures have all been more or less dissolved by the acetic acid. The chromosomes stand out, their structure unaltered, but with a peculiar highly refractive appearance. It is well to choose a particular chromosome for observation under a high power before running in the fuming hydrochloric acid. The action of this reagent is very sudden. The chromosome retains its solid homogeneous appearance for some time, but then swells up, and for a few moments shows two spongy segments, each clearly outlined by a broken black line. The twist of these segments on each other is quite clear, but the whole chromosome disappears very quickly. Chromosomes fixed in Hermann's solution cannot be dissolved in this way.

The disappearance of the nuclear membrane and the formation of the spindle can often be beautifully traced in the mother-cells of a single loculus. Fragments of nucleolar matter can sometimes be seen among the chromosomes after the nuclear membrane has gone. At the same time a number of large erythrophilous granules appear in the cytoplasm (Fig. 10 a). These are doubtless of nucleolar origin.

The chromosomes seem driven together in a heap on the disappearance of the boundary between nucleus and cytoplasm (Fig. Io a). The spindle-fibres soon make their appearance at two or three points in the cytoplasm (Fig. 10 a), whence

1 E. Zacharias, Ueber das Verhalten des Zellkerns in wachsenden Zellen, Flora, 1895, Ergänzungsband, p. 24I. Quoted in Zimmermann's Morphologie und Physiologie des pflanzlichen Zellkernes, I896, p. 27.

${ }^{2}$ Strasburger, Ueber Kern- und Zelltheilung, I 888, p. I 46. 


\section{Sargant.-Formation of the Sexual Nuclei}

they extend towards the chromosomes. The spindle thus formed is rarely symmetrical at first (Figs. IO $a$, I I, II $a)^{1}$. The chromosomes soon begin to scatter, being attached to bundles of fibres (Fig. I I $\alpha$ ).

As the spindle becomes symmetrical, the chromosomes are arranged in an equatorial plate. Two very well-marked bundles of spindle-fibres are then attached to each chromosome (Fig. I2) ${ }^{2}$. One of these bundles is fixed to each segment, and they point to opposite poles. The two segments move apart from each other as if each were pulled to its pole by the fibres attached to it. During the process of separation the whole chromosome becomes much contorted. This is not surprising when we consider how tightly the segments of each chromosome are usually twisted on each other, and that they must untwist as they are pulled apart. Adjacent chromosomes may assume very different shapes (Fig. I2). This depends very much on the point of attachment of the spindle-fibres, which may be in the middle of the chromosome or near one end. The knotted and strained appearance of the segments just before complete separation is much less conspicuous here than in the first division of the embryo-sac nucleus (I, p. 462). Compare for instance Fig. I3 in this paper with Fig. 23 in Part I. It seems as if the strength of the pull exercised on the chromosomes by the spindle-fibres varied to some extent with the size of the cell.

The daughter-chromosomes in the diaster-stage are commonly $\mathrm{V}$-shaped, the angle pointing towards the pole which it approaches (Figs. I3, I4). This angle is often bent back (Fig. I4) ${ }^{3}$. When the two groups of daughter-chromosomes reach the poles, they cluster closely together, and the deflexed angle forms part of a depression in the daughter-nucleusthe 'polfeld.' A cell-plate is formed between the two nuclei (Fig. I 5), and is shortly followed by a cell-wall.

\footnotetext{
' W. Belajeff, Zur Kenntniss der Karyokinese bei den Pflanzen, Flora, Ergänzungsband, 1894, p. 438 .

${ }^{2}$ W. Belajeff, 1. c. p. 439. See particularly Fig. I 5 from L. candidum.

${ }^{3}$ See Postscript.
} 
in Lilium Martagon: II. Spermatogenesis. 205

The number of the chromosomes taking part in the first karyokinesis of the pollen-mother-cell nucleus is most easily counted while they form a nuclear plate. A single longitudinal section from an anther of the right age contains hundreds of such figures, but there is some difficulty in exact counting, because the chromosomes are crowded on the spindle. I finally adopted the following method:- Two hand-sections were closely examined for spindles more or less perpendicular to the plane of the section. Before any attempt was made to count the chromosomes, certain tests were applied to each figure. The objective was raised until the whole nuclear plate was indistinct. If no part of the section in its neighbourhood was then in sharp focus, the figure was rejected. The same test was applied with a lowered objective. The object of both was to exclude nuclear plates lying on either surface of the section, for chromosomes lying above or below the others might have been removed from such figures in cutting the section. Nuclear plates which stood these tests, but in which the chromosomes were crowded together on one side, were also rejected. Twenty nuclear plates were chosen in this way.

\begin{tabular}{|c|c|c|c|c|}
\hline In 9 cases & re & vere certainly & I 2 & chromosomes \\
\hline ", 9 cases & , & either & I I or I 2 & " \\
\hline ", I case & $"$ & $"$ & I 2 or 13 & $"$ \\
\hline , I case & ," & , & IO, II or I 2 & " \\
\hline
\end{tabular}

The daughter-nuclei formed by the first division never enter the resting-stage. Each is merely a close knot of chromatic ribbon, without nucleoli but enclosed in a nuclear membrane which disappears in the earlier stages of karyokinesis.

When a daughter-nucleus is about to divide, it begins to swell up, and its chromatic coils become looser. As they separate, a certain symmetry is seen in their arrangement (Fig. I6). The coils now become stretched in the direction of the axis of the future spindle (Fig. I 7 ); but the distortion is very slight compared to that of the corresponding stage in the micropylar daughter-nucleus of the embryo-sac. There the young chromosomes have a knotted and strained appearance, which is absent from those we are considering (cf. Fig. 


\section{Sargant.-Formation of the Sexual Nuclei}

29 in Part I with Fig. 18 in this part). Another difference must also be mentioned. In the embryo-sac the young chromosomes when just formed from the spirem-ribbon are of different shapes, often hooked at one or both ends (I, Fig. 29). Most of those formed from the daughter-nucleus of the pollen-mother-cell are alike and of a perfectly definite shape, which may be described as a $\mathrm{V}$ with the angle bent back (Fig. I 8, Nos. I, 2, 3, 4, 5, and 9). This is the characteristic form of the diaster-segments in the previous division (Fig. 14). A few are irregularly twisted (Fig. I 8 , Nos. 6 and 7), and others still show the median bend characteristic of the V-shape, though they are straightening out (Fig. I 8, No. 8). This peculiarity of shape suggests that the daughter-chromosomes of the first division have retained their identity within the daughter-nucleus.

The chromosomes do their best to form an equatorial plate as soon as the spindle is formed. They are necessarily much crowded together. The whole pollen-mother-cell was barely large enough for the spindle of the first karyokinesis. The chromosomes which take part in the second are fully as long as the mother-chromosomes, though less thick. But the pyramidal mother-cell has been divided by a partition into two compartments of awkward shape. The spindle formed in each is usually more or less distorted to fit it (Figs. 20, 22). The long slender chromosomes have to fit as best they may into the equatorial zone of this spindle (Fig. 20).

This crowding together of the chromosomes on the spindle makes observation of the details of karyokinesis somewhat difficult. At least two different accounts have been given of the way in which actual separation of the chromosomesegments takes place ${ }^{1}$. I have found thick sections useless, because in a preparation which includes the whole of a nuclear plate one chromosome cannot be distinguished from another. Very thin sections are apt to be misleading, as they rarely

1 (I) Guignard, Nouvelles Études sur la Fécondation, p. I 76 ; J. B. Farmer, Ueber Kerntheilung in Lilium-Antheren, Flora, 1895, p. 67. (2) Strasburger, Botanisches Practicum, III. Aufl. p. 6r I. 
include a complete chromosome. Sections about $7.5 \mu$ thick from Hermann-material are the most useful, and it is well to compare them with others about $5 \mu$ thick. Figs. I6-22 are drawn from such preparations. Of these, Figs. 20 and 22 give the general appearance of the nuclear section as faithfully as I can render it. The others are slightly diagrammatised by the omission of such chromosomes and fragments as would make the figure obscure. In doing this I have of course been influenced in retaining or omitting detail by my own interpretation of the structure. This interpretation is based on very careful study of every detail in the karyokinesis.

Most of the chromosomes retain their characteristic shape throughout the process of division (Figs. 19 and 21). The angle of the $\mathrm{V}$ lies in the equatorial plane of the spindle, and the legs usually point outwards or towards one pole or the other (Fig. I9). Occasionally the legs point towards different poles, and then the $\mathrm{V}$-shape is lost, though the chromosome retains traces of its original form (No. 8 in Fig. 18 , and the middle chromosome in Fig. 19). One result of this arrangement is, that when the chromosomes of a whole nuclear plate are seen sideways there seem to be more than twelve, for it is easy to mistake each leg of the $\mathrm{V}$ for a separate chromosome. The whole of the spindle is not shown in the nucleus to the right of Fig. 20, yet fifteen free ends can be counted on it. Besides the $\mathrm{V}$-shaped chromosomes, there are usually two or three in each spindle which are straight or irregularly twisted. One end of such a chromosome commonly lies in the equatorial plane, and longitudinal fission of the segments begins there, as is the case also in vegetative nuclei. The segments of $\mathrm{V}$-shaped chromosomes are also formed by longitudinal fission, but they begin to separate at the angle (Fig. 2I). Hence most of the diaster-segments are V-shaped, but a few are hooked (Fig. 22). The reconstruction of the daughter-nuclei from the diastersegments goes on in the usual way, and is shortly followed by the formation of a cell-wall between them. Each of the four segments of the mother-cell rounds itself off and begins an independent existence as a young pollen-grain, but for 


\section{Sargant.-Formation of the Sexual Nuclei}

some time the envelope of the pollen-mother-cell is still visible round each group of four.

We have now traced the history of the four pollen-grain nuclei through all the steps of their development from the nucleus of the pollen-mother-cell. We have seen that the chromosomes of this nucleus showed at one period a complete division into two segments and an incomplete division of each segment into two. We have seen the two segments separated from each other during the first karyokinesis of the pollen-mother-cell nucleus. It is natural to inquire whether the subsequent division of these segments in the second karyokinesis does not correspond with the incomplete fission visible in each segment before the first took place. This question, however, I am unable to answer. It is difficult to believe in a sudden and complete change of structure in each chromosome at the time when its colouring becomes uniform (p. 202). But no trace of fission can be seen in the segments after that period. It might be possible to trace it from one karyokinesis to the other by microchemical methods, for there is no intervening period of rest, but the few experiments I have tried gave no conclusive result. Whether the daughtersegments separated during the second karyokinesis are formed de novo shortly before separation, or whether they date back to an earlier period, they are equally the result of longitudinal fission.

\section{Formation of the Male Pronucleus.}

The young pollen-grains are soon set completely free within the loculus of the anther by the disappearance of the mothercell envelope. No further change takes place in the nucleus of each grain for some time, during which the exine becomes thickened and beautifully sculptured on the outer surface (Figs. 23 and 27). The pollen-grain meanwhile grows considerably in length and assumes a curious shape (Fig. $23 a$ and $b$ ). The resting-nucleus can hardly find room within it, and is often flattened (Fig. $23 b$ ). There is a deep fold in the 
exine, and the inmost part of it continues unthickened. Thus, when the pollen-grain swells up later on, there is a thin region in the otherwise much thickened exine, which is shaped like a narrow gore in a balloon (Figs. 23, 27, 3I).

The nucleus of the pollen-grain divides once before it is mature. It is not always easy to hit on anthers in which this division may be seen. Strasburger's classical method for determining the stage of the pollen-mother-cell nucleus ${ }^{1}$ is not applicable here, for the exine of the pollen-grain is already perfectly opaque, and even if the stain should penetrate, the nucleus would not be visible. I could not succeed in making the exine transparent by the use of chloral hydrate or other clearing agents. It is out of the question to cut sections by hand without previous embedding, for the pollen-grains fall out of the loculus at once. Thus the only plan was to embed anthers of different ages and cut test sections from each with the microtome. In this way, after many failures, I succeeded in finding the pollen-grain nuclei in the act of dividing. This occurs at a period when the anther is bright orange, but before it has assumed the characteristic red tint. The filamenthitherto so short that the anther may be called sessile-has just begun to grow rapidly.

The pollen-grains in which nuclei are dividing are not arranged in a series within the loculus. On the contrary, one containing a single resting-nucleus may be found surrounded by others which present every stage of division. Here, as in the embryo-sac, there is no independent evidence by which to determine the seriation of stages. The nuclei are small, and there is some difficulty in obtaining clear differentiation by the ordinary staining methods. The figures which give detail (Figs. 25-27) are all from the same preparation, a series of sections $5 \mu$ thick cut from material fixed in alcoholic Hermann's solution. In one slide of this series the staining has been a success, and all the details in the structure of the chromosomes are quite clear. The cytoplasm is very lightly coloured however, and for details of its structure I have

1 Botanisches Practicum, III. Aufl. p. 609. 


\section{Sargant.-Formation of the Sexual Nuclei}

referred to another series, cut from absolute alcohol-material and stained with Renaut's haematoxylic eosin (Figs. 24, 28).

The daughter-chromosomes separate exactly as in vegetative nuclei. Indeed, this is the most typical of the five homotype divisions. The series of diagrams headed 'homotype' in Plate XI are founded on the vegetative karyokinesis (I, p. 45 I), but they might have been drawn equally well from the division we are now considering. The longitudinal fission of the chromosomes is perfectly clear (Fig. 27).

Both the resting and the dividing nucleus are invariably found close to one wall of the pollen-grain. The spindle is not unusually short. Its long axis is at right angles to the cell-wall near which it lies (Fig. 28). But during the dispirem-period the connecting threads look as if they were crushed between the two daughter-nuclei. The inner one is now much nearer than before to the outer, which is still close to the cell-wall.

I have never succeeded in seeing centrosomes, but a differentiated mass of cytoplasm is very conspicuous both at the inner pole of the spindle (Fig. 28) and on the inner side of the spirem-nucleus (Fig. 24). Radiations can often be traced from this mass into the surrounding cytoplasm. The latter shows a honeycomb-structure very clearly (Figs. 24, 28), but this may possibly be due to imperfect fixing. The exine offers considerable resistance to the penetration of fixing agents.

. The two daughter-nuclei continue to lie very close to each other for some time after the connecting threads have disappeared. A difference in size very soon becomes apparent. The generative nucleus is the smaller, and in the mature pollen-grain it is enclosed within a lens-shaped naked cell (see M. Guignard's beautiful figure: Nouvelles Études, Plate X, Fig. 27). During the interval between the formation of two daughter-nuclei and the dehiscence of the anther, each pollen-grain swells so that the outline of its equatorial section is circular, and it also grows larger (cf. Fig. 30 with Fig. 28). No change takes place in the structure of the two resting-nuclei until the pollen-grain reaches the stigma where it will germinate. 
I have often watched hive-bees visiting plants of Lilium Martagon in search of honey: The flower when it first opens hangs downwards, the petals are quite flat, and the stigma is seen below them like the clapper of a bell. It is considerably longer than the stamens. Later on in the same day the petals curl up, leaving the circle of anthers exposed round the long pendulous stigma. The three older anthers usually dehisce about this time. Next morning all the anthers have dehisced, but the stigma still hangs downwards. A bee in search of honey climbs in by the petals and clings to the stamens while it is sucking. Thus the under side of its body gets well dusted with pollen from the versatile introrse anthers, but the stigma is untouched. On the third morning, however, when the anthers have shed most of their pollen, the style bends upwards, and forms a convenient perch on which the honey-seeking bee may alight. In this way it is sure to be touched with pollen from the lower part of the bee's body. Bees invariably begin with the lowest flower of an inflorescence and work upwards. Cross-fertilization is ensured, as in the Foxglove, by the proterandry of the flowers and their centripetal arrangement on the stalk.

The stigma of Lilium Martagon is three-lobed, and each lobe is outlined by a depression in the stigmatic surface. It is also bisected for a part of its length by a cleft, the three clefts meeting in the centre of the stigma and running down into the channel of the style (Fig. 29). On either side of each cleft is a slight ridge, covered, like the rest of the stigmatic surface, with stigmatic hairs. More pollen is commonly deposited on the ridges bordering the two upper clefts in the upturned stigma than on the ridges of the third.

It is a laborious business at best to hunt for dividing generative nuclei in pollen-tubes creeping among stigmatic hairs. I have identified such stages most easily in handsections from alcohol-material. The stigma is cut from the style about a millimetre below the stigmatic surface, and the thick slice thus obtained is stained en bloc with a dilute solution of Mayer's haemalum in $\cdot 1 \%$ potash alum. It is 


\section{I Sargant.-Formation of the Sexual Nuclei}

dehydrated in the usual way, cleared in clove-oil, and examined in xylol under a simple microscope. The lobes are separated, and those only are used which are well covered with pollengrains. Sections are cut between slices of pith in a direction perpendicular to the cleft in the lobe, razor and material being kept wet with xylol. The sections are mounted at once in Canada-balsam, and examined with an immersion objective. It is easy to find pollen-tubes and germinating pollen-grains containing the generative nucleus in the spirem-condition without nucleolus or nuclear membrane, but later stages are rare. Some stigmas which had been cut and fixed between half-past one and two o'clock on a sunny day gave me the best results.

Very soon after the pollen-grain reaches the stigma, the spirem-ribbon is differentiated in the generative nucleus. The vegetative nucleus continues in the resting-state (Fig. 30). The pollen-tube grows out at the place where, as we have already seen, there is a thin-walled stripe or gore in the exine (Figs. 30 and $30 \mathrm{a}$ ). It pushes downwards among the stigmatic hairs, on the top of which the pollen-grain rests. The tube twists over and round these hairs until it reaches their base and crawls between them. When the pollen-grain is thus firmly anchored to the stigma, its nuclei enter the tube, the vegetative nucleus usually going first ${ }^{1}$. Sometimes the upper end of the pollen-tube remains within the exine until the cellcontents have travelled away from both. In other cases the exine may fall off (as in Fig. $3 \mathrm{I}$ ), and the turgid pollen-tube stand nearly upright on the stigma ( $p . t$. Fig. $3 \mathrm{I})$. The division of the generative nucleus is most easily observed when it takes place within such an up-standing tube (Figs. 32, 33 ), or when, as sometimes happens, the pollen-grain has fallen on the very edge of the cleft down which it must plunge, so that its course is perfectly straight from the beginning. Very often, however, this division is postponed until both nuclei are creeping among the bases of the stigmatic hairs; in that case, 
the dividing figures are more or less distorted and obscure. The division of the generative nucleus generally takes place soon after the formation of the pollen-tube ${ }^{1}$. It is already complete in one of my preparations which shows a germinating pollen-grain with a tube of very moderate length (Fig. 34). In this instance the vegetative nucleus looks as though it were in the act of dividing by the direct method, but I have never identified two nuclei at the end of a tube.

Longitudinal fission of the chromosomes is apparent at a comparatively early period in the history of the generative nucleus. It is very clear in the preparation from which Fig. 33 was drawn, and I have seen it unmistakably in six other cases. One of these shows the chromosomes much twisted round each other, and evidently only just formed from the spirem-ribbon. Stages intermediate between those shown in Figs. 33 and 34 are, however, wanting in my preparations. One section which contained a nucleus rather older than that of Fig. 33, the chromosomes being shorter and broader, and the fission in each even clearer, was lost in an attempt to restain it. The absence of such later stages is of the less importance, as M. Guignard has figured two in the memoir from which I have quoted so often already (Plate XI, Figs. 33, 34). The stages I possess are conclusive as to the fact of longitudinal fission of the chromosomes.

As we have seen, the pollen-grains are usually brushed on to ridges in the neighbourhood of the clefts in the stigma. The pollen-tubes have therefore no great distance to travel in search of them. By the time a tube has reached the nearest cleft, it usually contains three nuclei. The vegetative nucleus is more or less disorganized at the end of the tube. The two generative nuclei are exactly alike, each enclosed in its own envelope of protoplasm (Fig. 34). Neither nucleus possesses a nucleolus or a membrane; they are both in the form of a naked spirem, and they continue thus throughout their journey down the style. M. Guignard has pointed out that 


\section{I4 Sargant.-Formation of the Sexual Nuclei}

they increase in size during this period, and are much compressed in the narrow pollen-tube ${ }^{1}$.

In describing the three later nuclear divisions of the spermatogenetic series, I have said nothing as to the number of chromosomes which take part in them. There were difficulties in the way of exact counting, but about twelve chromosomes are found on each spindle.

\section{Homotype And Heterotype Divisions.}

The four nuclear divisions included in the spermatogenetic series of Lilium Martagon have now been described in detail. One characteristic-and that the most important-they possess in common with each other, with the three oögenetic divisions, and with the ordinary vegetative division. In each of these cases the effect of the whole process of karyokinesis is to divide each parent chromosome into a pair of daughterchromosomes by longitudinal fission, and to build up duplicate daughter-nuclei from the duplicate sets of daughter-chromosomes thus formed.

Less uniformity is observed when we come to detail. The seven nuclear divisions of the spermatogenetic and oögenetic series are distinguished from all others by the possession of twelve chromosomes in place of twenty-four. Among these seven divisions thus naturally divided from the rest, two distinct types of karyokinesis are found. One differs from that of the vegetative nucleus only in the number of chromosomes. The other differs widely from the vegetative type in many respects besides that of number, and is characteristic of the first division in either series-that division in which the reduced number of chromosomes first appears.

I have already insisted sufficiently on the peculiar character of the first karyokinesis on either side. The fact that the nuclear divisions, occurring at so critical a period in the line of descent of both sexual nuclei, should not only differ from the usual type, but also resemble each other so closely, is

\footnotetext{
${ }^{1}$ Guignard, 1. c., p. 178 and Fig. 36.
} 
sufficiently remarkable. It must have some meaning. When an adequate explanation has been found, it will probably throw light on some of the problems of heredity. In the meantime we may define a difference which our knowledge is insufficient to explain.

The homotype process of karyokinesis is illustrated by the series of diagrams A-F on Plate XI. This is an ideal series, representing what might be expected of an imaginary nucleus, which should divide like a vegetative nucleus (I, p. 45I and Figs. I-8) while possessing only twelve chromosomes.

Professor Strasburger has described and figured a symmetrical arrangement of the coils in the spirem-form of nuclei from the endosperm of Fritillaria ${ }^{1}$. I am convinced that a similar arrangement exists in the much smaller vegetative nuclei of Lilium Martagon (B). The chromosomes when they first appear have a ribbon-like character, and retain traces of their late coiled arrangement in the spirem-nucleus (C). They contract and straighten out to a more regular form. Each is bent near one end which lies in the equatorial plane of the spindle. The other points to one of the poles. Longitudinal fission first appears in this stage (D). Later on the whole chromosome comes to lie more or less in the equatorial plane, and separation of the two halves begins at the end which is attached to the spindle (E). The diastersegments are necessarily hooked ( $F)$.

Each of the five homotypic divisions is now to be compared with the ideal series A-F.

(I) The division of the micropylar nucleus in the binucleate embryo-sac agrees with it in all but two points. This nucleus when in the spirem-form, and also the young chromosomes of the succeeding stage, are apt to be pulled out in the direction of the future spindle, thus concealing the symmetry of the spirem-coils (I, p. 464 and Figs. 28, 29). Besides this deviation from the type there is a second occasional variation. In a few chromosomes of the nuclear plate-one or two

${ }^{1}$ Strasburger, Ueber Kern- und Zelltheilung, I888, pp. 61 63, Taf. II, Figs. 2 and 3 . 


\section{Sargant.-Formation of the Sexual Nuclei}

perhaps on each spindle-the segments begin to separate from the middle instead of from one end, and in consequence these segments are V-shaped in the diaster (I, pp. 465-66: $\times$ Figs. $30,3 \mathrm{I})$.

(2) In the succeeding division-that of both micropylar nuclei in the four-nucleate embryo-sac-similar deviations from the type occur. The spirem is distorted, and an occasional chromosome begins to divide about the middle of its length. The latter variation, however, is much less common than in the previous division (I, p. 468).

(3) The second division of the pollen-mother-cell nucleus is by far the most aberrant form of the five. The spirem indeed is quite typical (Fig. I6). But the chromosomes are V-shaped from the beginning and regularly divide from the middle. One or two in each spindle may divide from one end. Consequently most of the diaster-segments are $\mathrm{V}$-shaped (Figs. 19 and 21).

(4) The nuclear division in the pollen-grain which divides the generative from the vegetative nucleus is typically homotype. It agrees in every stage with the ideal series (Figs. 24-28).

(5) Those stages in the division of the generative nucleus which I have seen-namely, spirem, segmentation, and early spindle-are certainly homotype. The spirem is compressed in the pollen-tube, but not violently distorted. Longitudinal fission appears rather early in the chromosomes. But the close likeness between Fig. 33 and Diagram D cannot be mistaken.

In describing the heterotype form of karyokinesis there will be no need to begin with an ideal series and afterwards discuss the deviations from it of the two nuclear divisons which follow that type. The diagrams G-M are founded on the first division of the embryo-sac nucleus. If they had been founded on the first division of the pollen-mother-cell nucleus, the size of the chromosomes would be greater in proportion to the spindle and the diameter of the nucleus. In all other respects the diagrams represent either division equally well. 
One important feature of heterotype karyokinesis is not represented in the diagrams. No indication is given of the long period of growth which ends in the formation of the spirem $(G)$. The most prominent character of this period is the occurrence within it of the contracted state called synapsis, already twice described in detail. I believe the physiological purpose of this condition to be the formation of the spirem-ribbon from a single row of chromatin-granules strung on a linin-thread. This row is divided longitudinally just before the contraction begins, and during that contraction the linin-ribbon, which separates the two rows of granules in the spirem-nucleus, is formed at the expense of the half-dissolved nucleolus (I, p. $45^{8}$, and II, p. 198).

The other features which distinguish heterotype from homotype divisions are fairly represented in the diagrams. They may be summarised here.

Differentiation of the spirem-ribbon. In Diagram G, as in $A$, the spirem-nucleus contains a coiled chromatic ribbon and one or more nucleoli within the nuclear membrane. But in A the ribbon appears to be homogeneous-its whole surface reacts in a uniform way to stains-and in $G$ it is differentiated. The ribbon itself is erythrophilous, but it bears on either margin a row of cyanophilous granules. There may even be some further differentiation. At certain periods in the development of the ribbon, it seems as if the borders on which the granules lie were of rather tougher material than the broad zone which separates them.

Early longitudinal fission of the chromosomes. In Diagram C the homotype chromosomes are seen to be formed of lengths of spirem-ribbon. Longitudinal fission follows later (D). In the heterotype nucleus the spirem-ribbon is first divided longitudinally and then falls into lengths. Thus each length consists of two separate linin-filaments, each bearing a single row of chromatin-granules $(\mathrm{H})$. The nuclear membrane and nucleolus disappear before segmentation in the homotype nucleus (B), but persist for some time later in the heterotype (I). 


\section{Sargant.-Formation of the Sexual Nuclei}

Second longitudinal fission of the chromosomes. The segments of homotype chromosomes appear homogeneous throughout the karyokinesis (D-F). Heterotype segments are differentiated shortly after their formation. Each consists of a length of erythrophilous ribbon bearing a row of cyanophilous dots on either margin (I). This differentiation disappears with the nucleolus and nuclear membrane. The segments then look homogeneous $(\mathrm{K})$. Whether any trace of the second fission remains in their structure is uncertain.

Contorted shape of the chromosomes in the muclear plate. The segments of the homotype chromosome are nearly parallel to each other, and they separate from each other with great regularity, usually from one end (E). This is not the case with the heterotype chromosome. The segments are tightly twisted on each other, they may separate from near the middle of the chromosome or (more rarely) from one end. The result is that the separating chromosomes are much contorted, and adjacent ones may be of a very different shape (K).

Shape of diaster-segments. As a necessary consequence of their method of separation, segments of homotype diaster are generally hooked $(\mathrm{F})$, the heterotype diaster-segments $\mathrm{V}$-shaped (M). No great importance is to be attached to this distinction.

\section{ApPEndix ON Methods.}

\section{A. FIXING.}

Anthers fixed in absolute alcohol were usually uncut. Those fixed in any of the three solutions given below were either halved transversely or cut at both ends to ensure penetration.

\section{Hermann's solution (alcoholic).}

I0 \% aqueous solution of platinic chloride 3 c.c.

I \% osmic acid (aqueous) . . . 8 c.c.

Glacial acetic acid . . . . 2 c.c.

Absolute alcohol . . . . . 27 c.c. 


\section{in Lilium Martagon: II. Spermatogenesis. 219}

The anthers were left in this solution for one and a half to two hours, and then transferred to a $5 \%$ aqueous solution of platinic chloride for twenty-four hours. They were then placed in a I \% aqueous solution of platinic chloride for twenty-four hours.

\section{Flemming's solution (aqueous).}

I \% aqueous solution of chromic acid . 30 c.c.

I \% osmic acid (aqueous) . . . 8 c.c.

Glacial acetic acid . . . 2 c.c.

The anthers were left in this solution for about two hours, and then transferred to an aqueous $\cdot 5 \%$ solution of chromic acid for eighteen hours.

Chromic acid (aqueous). The anthers were laid in a . $5 \%$ aqueous solution of chromic acid for eighteen to twenty-four hours.

After treatment in any of these ways, the anthers were rinsed in water, and transferred successively at intervals of about twelve hours to $30 \%, 50 \%, 70 \%$ alcohol, and finally left for several days in methylated spirit, changed as it became discoloured. These changes were made in the dark when the fixing solution had contained chromic acid.

The anthers were preserved in a mixture of equal parts absolute alcohol, glycerin, and distilled water.

\section{B. EMBEDDING AND CUTTING.}

For anthers fixed in mixtures containing chromic acid or platinic chloride, paraffin melting at $5^{2} \mathrm{C}$. is hard enough. A softer paraffin can be used for anthers fixed in absolute alcohol. I was able to cut sections I $_{5} \mu$ thick from such material embedded in paraffin melting at $45^{\circ} \mathrm{C}$.

The sections were usually floated on the slide with distilled water, and made to adhere by careful drying without cement. But in the case of anthers showing the nuclear division within the nearly mature pollen-grain, I used a cement of collodion and clove-oil, otherwise the sections of pollen-grains would have been washed away.

Great care must always be taken not to overheat the paraffinribbon on the slide. If the paraffin approaches its melting-point, the sections will be strained and their structure distorted.

Hand-sections are apt to be broken while they are being transferred from a stronger to a weaker solution of alcohol. To avoid this the 


\section{Sargant.-Formation of the Sexual Nuclei}

sections were placed in a small wide-necked bottle half filled with distilled water, on the top of which absolute alcohol had been poured gently. The alcohol floated for some time on the water, and the sections sank down through solutions of gradually increasing density until they lay in the pure water at the bottom. Then the alcohol was drawn off by a pipette.

\section{STAINING.}

I. Flemming's orange method for material fixed in Flemming's solution, Hermann's solution, or chromic acid.

There is little to add to the account given in Part I, p. 474. For early stages in the development of the pollen-mother-cell, the potassium permanganate was used as a mordant both before and after the treatment with safranin. The safranin and gentian violet solutions were also of double the usual strength for these stages. For later ones-as the first nuclear division in the pollen-mother-cell-the ordinary treatment was sufficient.

\section{Mayer's haemalum for chromic material.}

The sections were placed for half an hour in a. $5 \%$ solution of ferric chloride in water, rinsed and transferred to Mayer's haemalum, nearly full strength. They usually took about two hours to stain to the right depth. If the sections were kept alkaline by rinsing in hard water and by the use of neutral alcohols, they were of a brilliant blue and very permanent.

\section{Mayer's haemalum for absolute alcohol-material.}

The sections were treated as above, but with $\cdot \mathbf{I} \%$ solution of ferric chloride for half an hour, and $10 \%$ solution of Mayer's haemalum in .I \% solution of potash alum for about twelve hours.

\section{Methyl-green and acid fuchsin for alcohol-material.}

These colours were used in aqueous solution, their proportions varied to suit different stages.

\section{Renaut's haematoxylic eosin for alcohol-material.}

The same treatment as that given in Part I, p. 474, was used. 


\section{POSTSCRIPT.}

The twisted V-shape is characteristic of the diaster-segment in both heterotype divisions, and may easily give rise to misconception. Thus Professor E. B. Wilson (The Cell in Development and Inheritance, p. I97) has pointed out that one of my figures, representing a pair of such chromosomes en face, would suggest that each daughter-chromosome is already divided transversely. Such an appearance is in fact not uncommon, but in studying the actual preparation it can as a rule be quite clearly made out that the daughter-chromosomes are neither divided nor even constricted. They are usually contorted, however, by a sort of double twist near the middle of each. This may be more easily followed in the chromosomes of the first embryo-sac karyokinesis (I, Figs. 23 and 24. Compare especially the chromosomes $\mathrm{I}-4$ in Fig. 24 with those of Fig. 23 and with Figs. I 3 and 14 of this part). It will be seen later on that this twisted $\mathrm{V}$-shape reappears in most of the chromosomes belonging to the second karyokinesis in the pollen-mother-cell (Figs. I 8, I 9). No transverse division has therefore taken place since the first karyokinesis, nor is any indicated in the chromosomes of the daughter-nuclei, which shortly afterwards divide by longitudinal fission (p. 207).

Quarry Hill, Reigate, April 27, 1897 .

\section{EXPLANATION OF FIGURES IN PLATES $\mathrm{X}$ AND XI.}

\section{Illustrating Miss E. Sargant's paper on the Nuclei of Lilium Martagon.}

The figures marked $\times 5^{8} 5$ were drawn from Zeiss' apochromatic hom. im. objective, 2 m.m. focal length, N. A. I.30, with eye-piece 4 ; and those marked $\times 290$ and $\times 300$ with the same objective, eye-piece 2 . The figures marked $\times 1000$ were drawn under Zeiss' apochromatic hom. im. objective, $r \cdot 5 \mathrm{~m} . \mathrm{m}$. focal length, eye-piece 6 . Figs. $30 a$ and $3 \mathrm{I}$ iere drawn under Zeiss' apochromatic objective, $16 \mathrm{~m} . \mathrm{m}$. focal length, with eye-pieces 6 and 4 respectively. All these figures were outlined with the camera lucida and details added in freehand.

Fig. 29 was slightly enlarged by eye from a whole stigma. 


\title{
222 Sargant.-Formation of the Sexual Nuclei
}

\author{
PLATE $X$.
}

Figs. 1-15. First karyokinesis in pollen-mother-cell.

Fig. I. Pollen-mother-cell soon after its formation, with resting-nucleus. $\times 5^{8} 5$.

Fig. I $a$. Resting-nucleus from older mother-cell: $n$, nucleolus. At $\times$ the thread shows dots. $\times$ I000.

Fig. 2. Pollen-mother-cell with nucleus in which first signs of approaching synapsis are seen. The chromatic network begins to contract away from the nuclear wall to the right of the figure. Besides the vacuolated nucleolus, there is a shapeless mass of nucleolar matter to the left, which is green in the thicker part about $x$, but washy red at the edges. $\times 5^{8} 5$.

Fig. $2 a$. Bit of thread from nucleus of same age as that shown in Fig. 2, more highly magnified. The thread is irregularly thickened, and shows two rows of dots. At $n, n$, drops of nucleolar matter are attached to it.

Fig. 3. Pollen-mother-cell with nucleus in synapsis. A general view of the whole cell from a hand-section. The nucleolus is hidden by the close coils of the contracted chromatic thread. $\times 5^{8} 5$.

Fig. $3 a$. Section from nucleus rather older than that drawn in Fig. $3: n$, the nucleolus, now recovering its shape. There is still a good deal of amorphous nucleolar matter among the coils of the contracted chromatic thread. $\times 5^{8} 5$.

Fig. $3 b$. Bit of thread (from place marked $\times$ in Fig. $3 a$ ), more highly magnified. It is now of uniform breadth and the double row of dots is clear.

Fig. 4. Pollen-mother-cell with spirem-nucleus. From a hand-section. $\times 5^{8} 5$.

Fig. 4a. Tangential section from nucleus rather older than that of Fig. 4. The ribbon begins to be articulated. $\times 1000$.

Fig. 5. Pollen-mother-cell with nucleus in which the spirem-thread has begun to split longitudinally $\left(\mathrm{x}^{\prime}\right): n$, nucleolus. $\times 585$.

Fig. 5 a. Tangential section from nucleus in which the splitting of the ribbon is almost complete. $\times 1000$.

Fig. 6. Pollen-mother-cell in which the spirem-ribbon of the nucleus has begun to fall into lengths, as at $\times$. Longitudinal fission is already complete: $n$, nucleolus. From the same hand-section as Fig. $5 . \quad \times 585$.

Fig. 7. Pollen-mother-cell with nucleus, in which the twelve double filaments formed from the spirem-ribbon have begun to cluster round the half-dissolved nucleolus. The nuclear membrane is indistinct, and much of the sap is coloured by the nucleolus. $\times 5^{8} 5$.

Fig. 7 a. Section of nucleus nearly the same age as that shown in Fig. 7 . From a series of thick sections $(15 \mu)$ from alcohol-material. All the phenomena of synapsis have reappeared. $\times 1000$.

Fig. 8. Pollen-mother-cell from same section as Fig. 7. The optical section of the nucleus probably passes through the smallest diameter of the nucleus. The filaments are shorter and thicker; probably each consists of a double row of dots, but the section is too thick to make this certain. The nucleolus assumes its definite outline and the nuclear membrane reappears. $\times 5^{8} 5$.

Fig. $8 a$. Part of a single pair of filaments from a nucleus rather older than that shown in Fig. 8. Each filament is irregularly thickened and bears a double row of dots. Magnified about 1000 times.

Fig. 9. Pollen-mother-cell from a thin serial section. The immature chromosomes consist of two twisted lengths of linin-ribbon, each bearing two rows of 
chromatin-granules : $n$, nucleolus, round which some of the chromosomes are still clustered. $\times 5^{8} 5$.

Fig. 9 a. Single immature chromosome from nucleus about same age as that of Fig. 9, more highly magnified.

Fig. I0. Pollen-mother-cell from thick serial section ( $\left.5_{5} \mu\right)$. The chromosomes are nearly mature : $n, n$, fragments of nucleolus. $\times 5^{8} 5$.

Fig. Io $a$. Pollen-mother-cell from serial section (Io $\mu$ thick). The spindle is just appearing; part of the nuclear membrane is still seen at $x$. Small drops, probably of nucleolar matter, are visible in the cytoplasm. $\times 5^{8} 5$.

Fig. II. Pollen-mother-cell from same section as Fig. 10. The asymmetrical spindle is just formed. $\times 5^{8} 5$.

Fig. I I $a$. Pollen-mother-cell from thick serial section $($ I $2.5 \mu)$. The spindle is still asymmetrical, and though the chromosomes are attached to the spindlefibres, they are not as yet arranged in an equatorial plate. $\times 5^{8} 5$.

Fig. I 2. Pollen-mother-cell from thin serial section $(7 \cdot 5 \mu)$. Part of the nuclear plate is seen tangentially. $\times 5^{8} 5$.

Fig. I3. Pollen-mother-cell from thin serial section $($ Iо $\mu$ ). Four chromosomes are seen just before the separation of their segments is complete. $\times 585$.

Fig. I4. Pollen-mother-cell from same preparation as Fig. I2. The daughterchromosomes are formed and on their way to the poles. Each is V-shaped, with the angle more or less bent back. $\times 5^{8} 5$.

Fig. I5. Pollen-mother-cell from same anther as Figs. I 2 and I4. Two daughter-nuclei are formed with cell-plate between them. $\times 5^{8} 5$.

Figs. 16-22. Second karyokinesis in pollen-mother-cell.

Fig. 16. Tangential view of daughter-nucleus in spirem-stage. $\times 1000$.

Fig. I 7. Similar view of rather older nucleus. The coils are being pulled out in the direction of the future spindle. $\times 1000$.

Fig. I 8. Nine chromosomes formed from the spirem-daughter-nucleus. Nos. I, $2,3,4,5$, and 9 are $\mathrm{V}$-shaped. $\times$ Iooo.

Fig. 19. Five chromosomes on spindle of daughter-nucleus. All show V-shape. $\times$ I 000 .

Fig. 21. Two chromosomes from nuclear plate of daughter-nucleus just as segments are separating. $\times$ I000.

\section{PLATE XI.}

Fig. 20. Pollen-mother-cell divided into two compartments, each containing a nuclear plate. $\quad \times 5^{8} 5$.

Fig. 22. Pollen-mother-cell divided : the nucleus of each daughter-cell has formed a diaster. $\times 5^{8} 5$.

Figs. 23-28. Karyokinesis of pollen-grain-nucleus.

Fig. 23. Sections of immature pollen-grain, (a) parallel to long axis, (b) perpendicular to long axis. $n$, nucleus. $\times 300$.

Fig. 24. Section of pollen-grain with nucleus in which the spirem-ribbon is formed. A differentiated mass of cytoplasm is seen near the nucleus. $\times 5^{8} 5$.

Fig. 25. Tangential view of nucleus in spirem-stage : $n$, nucleolus. $\times 1000$.

Fig. 26. Five chromosomes arranged on spindle. Longitudinal fission not yet apparent. $\times 1000$. 


\section{Sargant.-Sexual Nuclei in Lilium Martagon.}

Fig. 27. Four chromosomes on spindle. The segments of each are in the act of separating. $\times$ I000.

Fig. 28. Section of pollen-grain in which the daughter-chromosomes of the dividing nucleus are just separating. At the inner pole is a differentiated mass of cytoplasm. $\times 585$.

Figs. 29-34. Karyokinesis of generative mucleus in pollen-tube.

Fig. 29. Stigma slightly enlarged.

Fig. 30 . Section of pollen-grain in situ on stigma and just about to put out tube: $v . n$. vegetative nucleus; $g . n$. generative nucleus already in spirem-stage. $\times 585$.

Fig. $30 a$. Empty shell of pollen-grain with remains of tube, from dissection of stigma. $\times$ I00.

Fig. 3r. Stigmatic hairs with pollen-grains germinating among them: p.t. tube from which exine $(e x)$ has fallen off, and containing generative nucleus $(g . n$.$) ;$ $p . g$. pollen-grain which has put out coiled tube. $\times 66$.

Fig. 32. Pollen-tube containing generative cell in which generative nucleus is on the eve of forming chromosomes from lengths of spirem-ribbon. $\times 1000$.

Fig. 33. Pollen-tube in which generative nucleus has formed twelve chromosomes, each divided longitudinally. $\times$ 1000.

Fig. 34. Germinating pollen-grain from dissection. Three nuclei. $\times 290$.

\section{DIAGRAMS.}

The two series of diagrams illustrate the difference between the heterotype process of nuclear division in Lilium Martagon and the homotype process.

The homotype series is founded on drawings of the vegetative nuclei which are seen in tissues of the young ovule and ovary (I, p. 45I). They are drawn as though each nucleus had twelve chromosomes in place of twenty-four.

The heterotype series is founded on drawings from the first division of the embryo-sac nucleus. The spindle is drawn on the same scale as the homotype spindle, which makes the heterotype chromosomes appear smaller than the homotype chromosomes. For the ratio of spindle-length to chromosome-length is greater in the heterotype than in the homotype karyokinesis. 


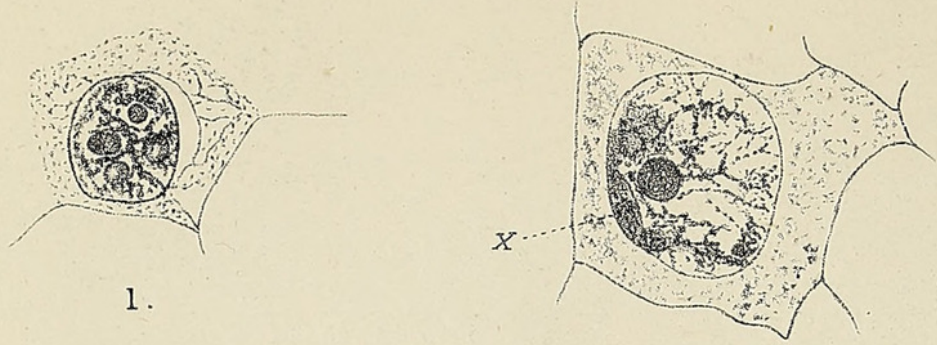

2.

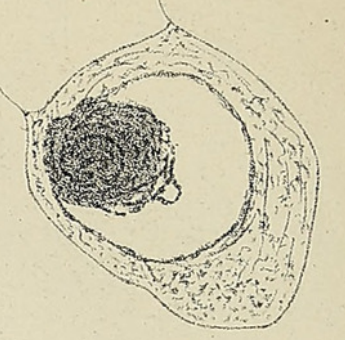

3.
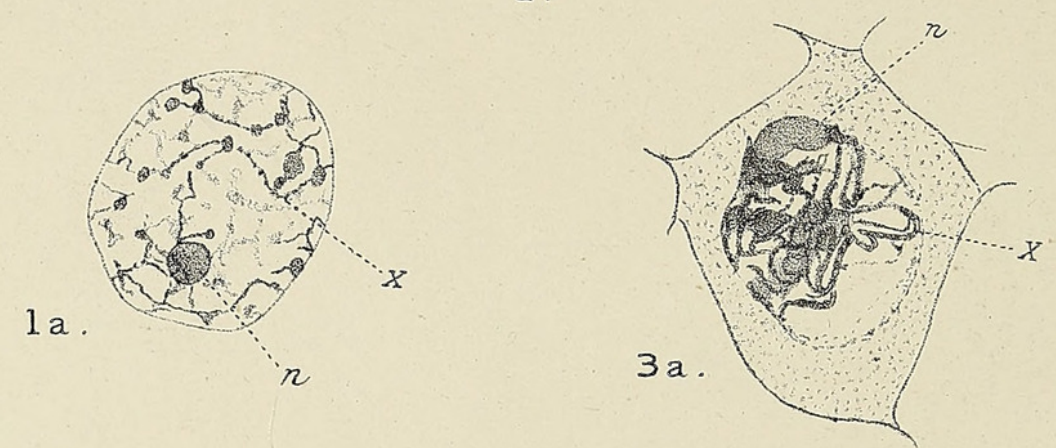

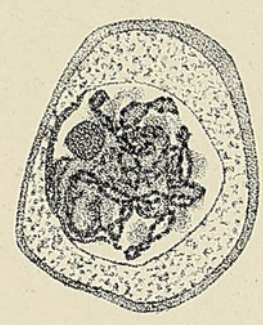

8.
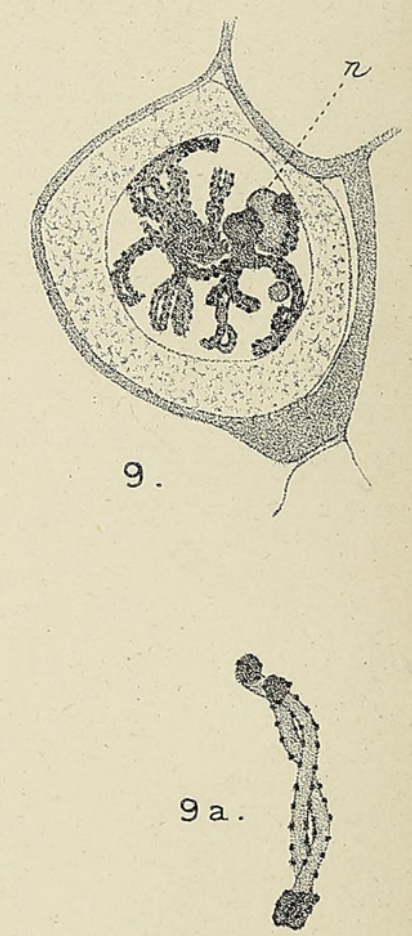

13

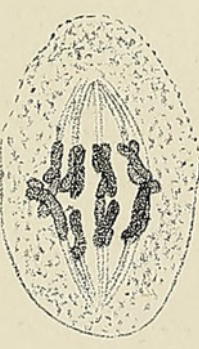

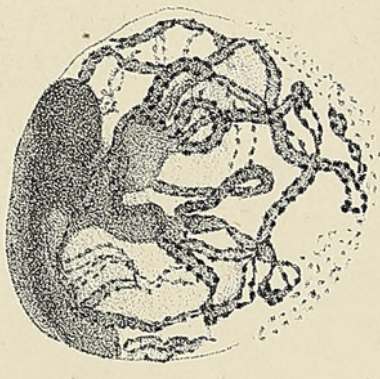
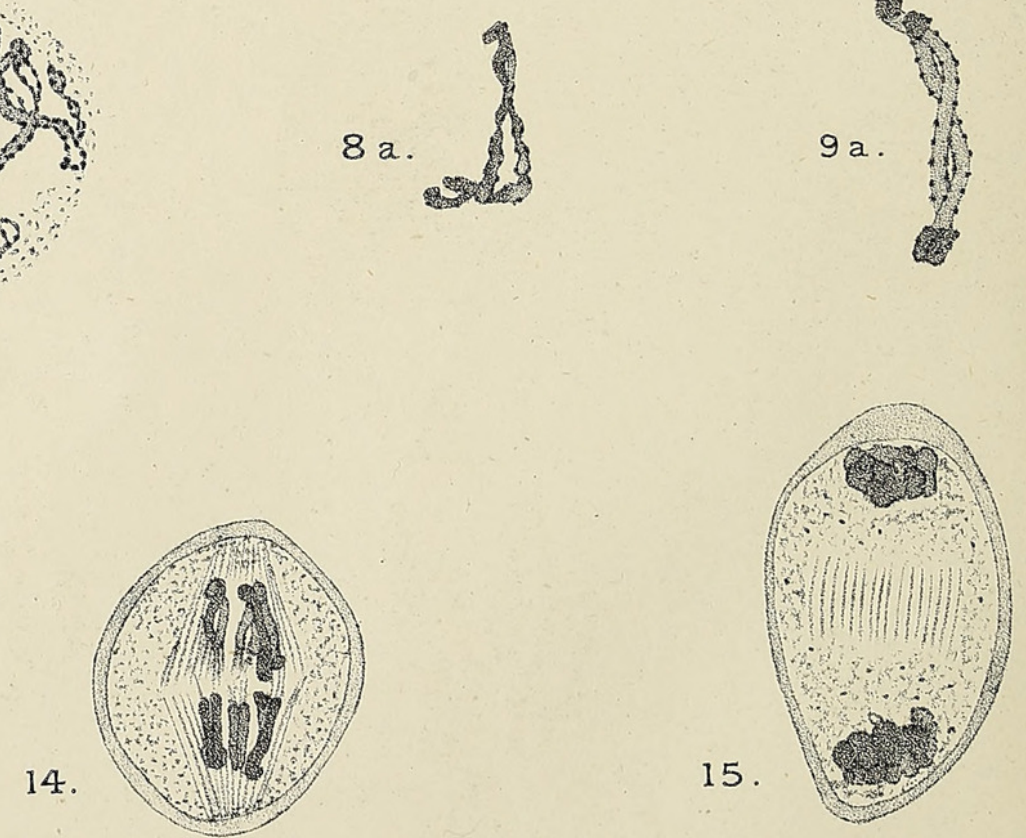

E. Sargant del. 

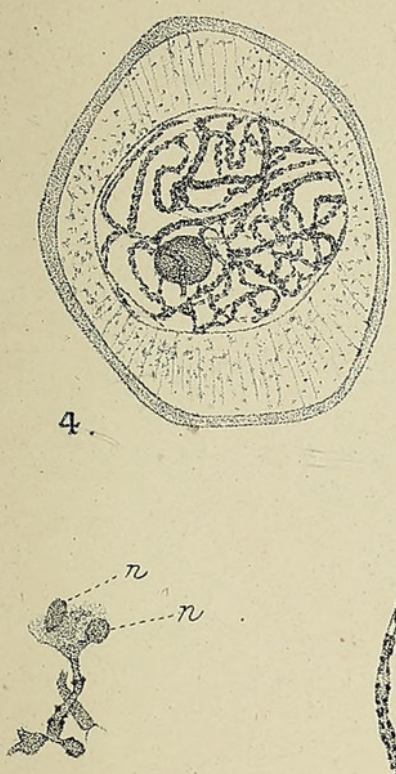

$2 a$.
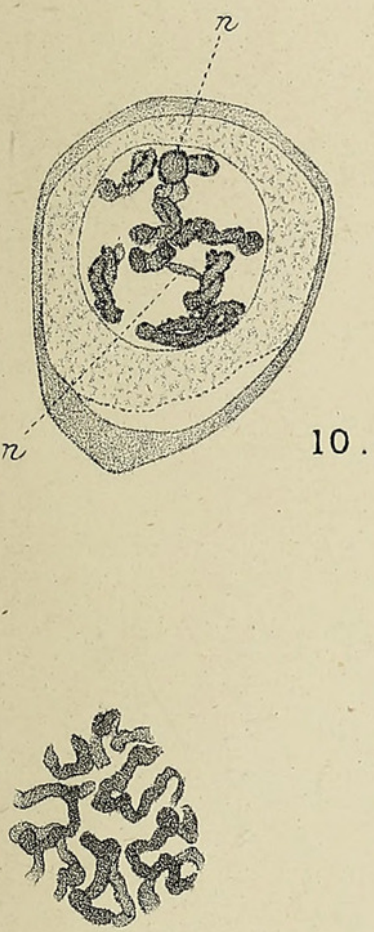

16.

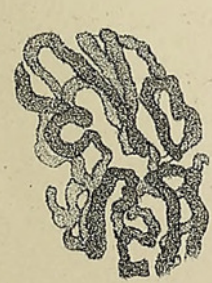

17.

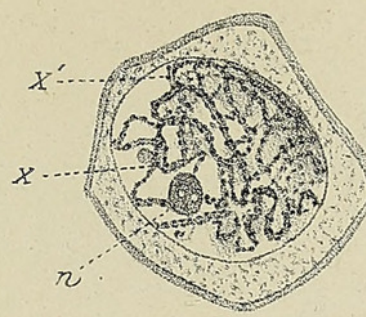

5.
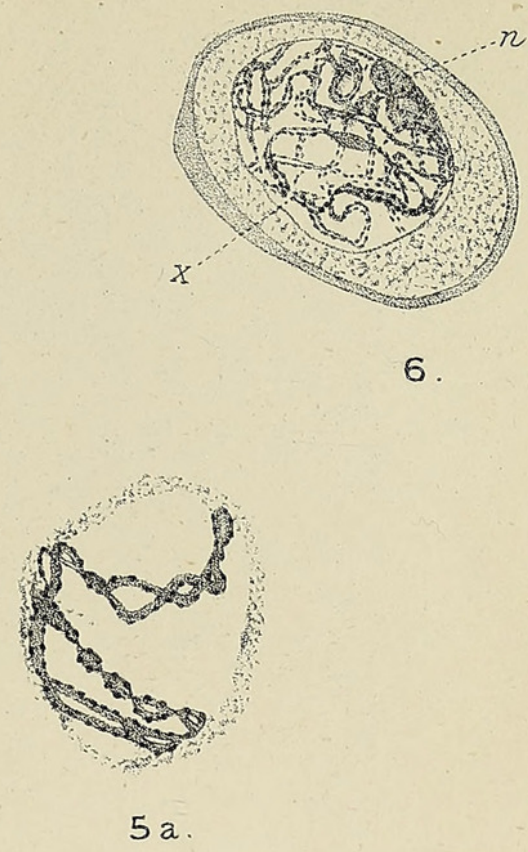

12

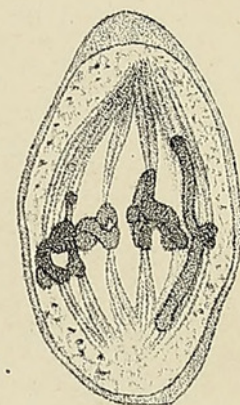

11.
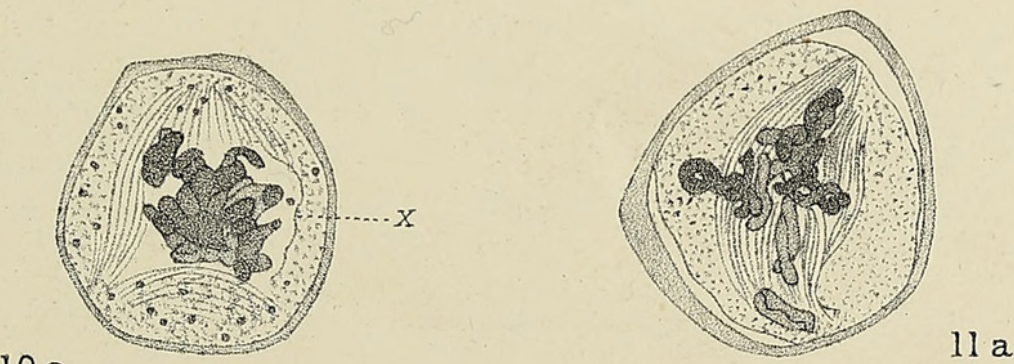

$11 a$

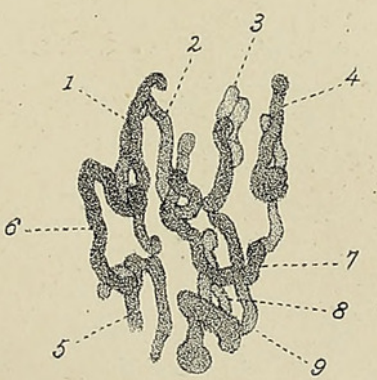

18.

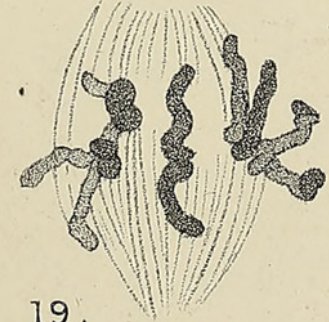

19.

21.

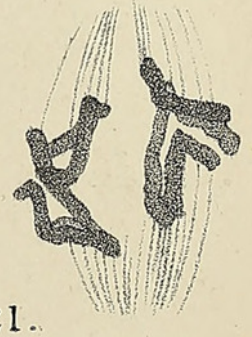

University Press, Oxford 


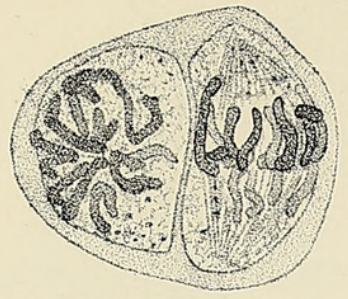

20.

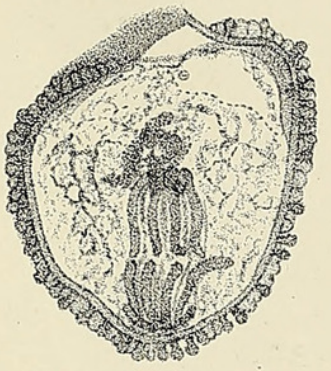

28
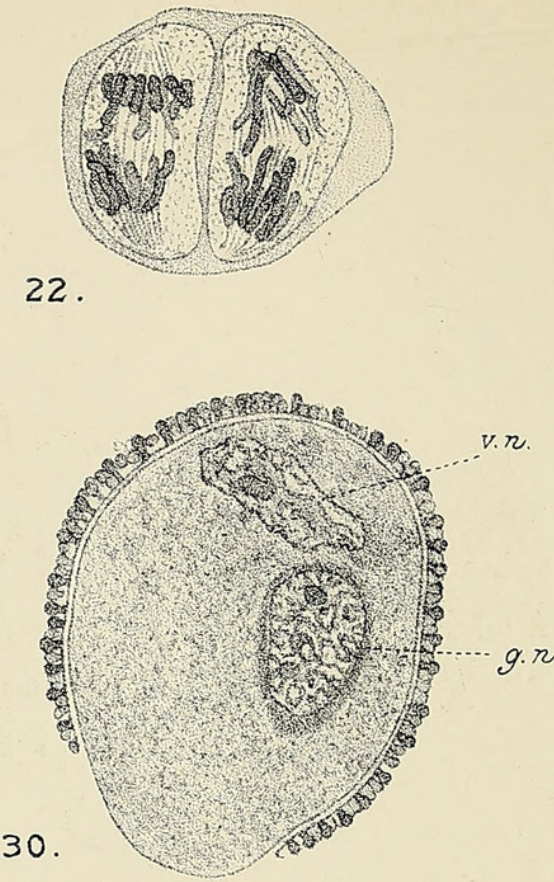

24

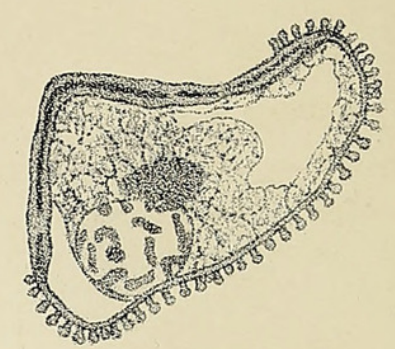

23.

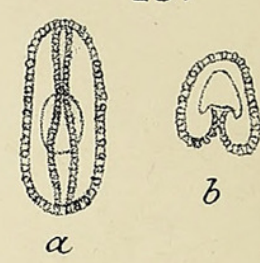

29.

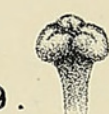

Diagrams founded on the Nuc

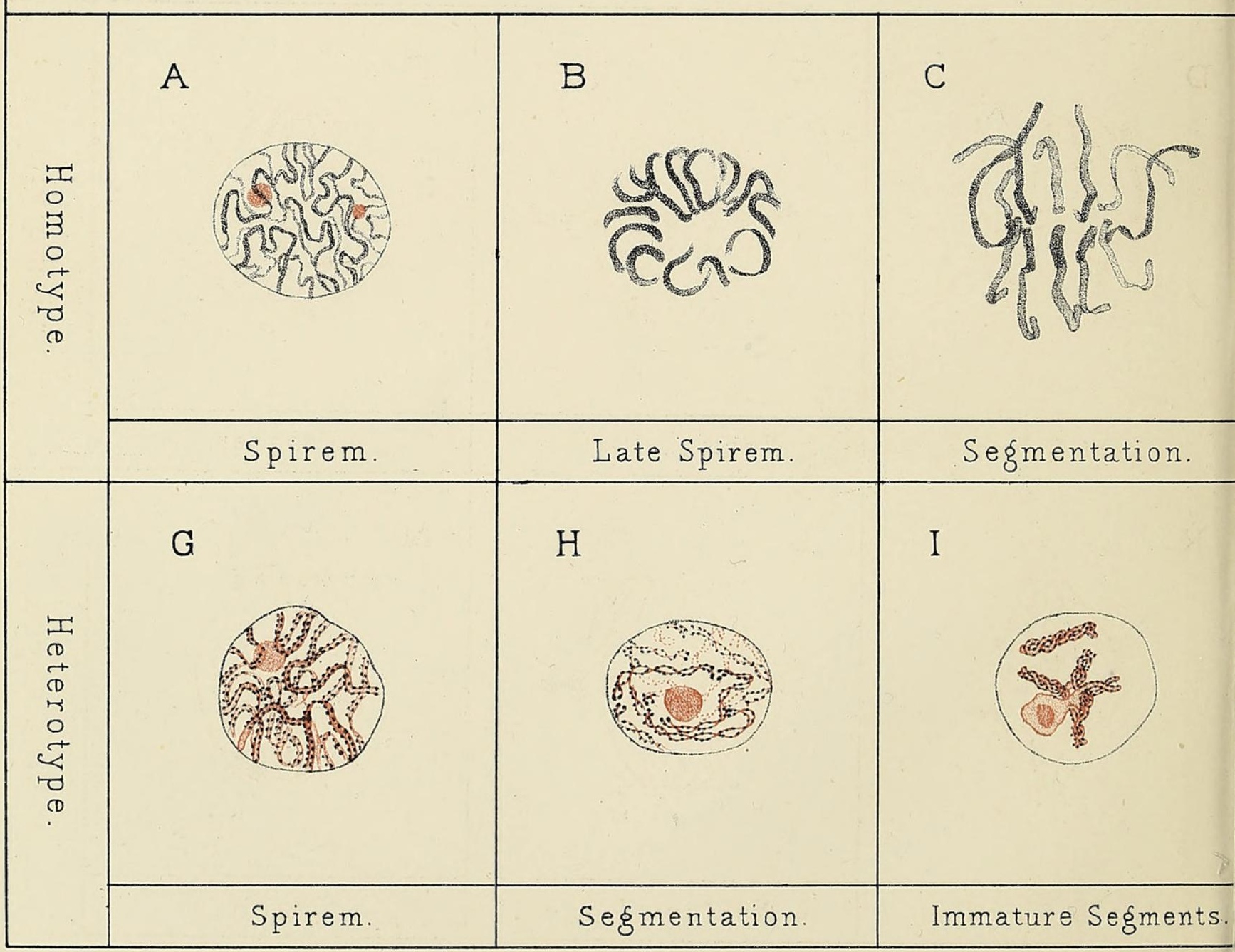

E Sargant del 

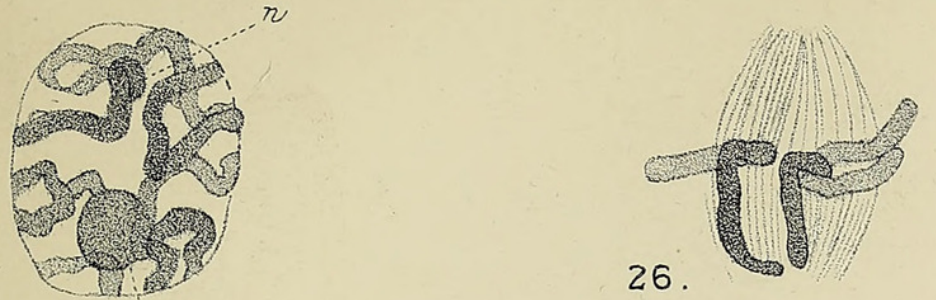

25.

st.
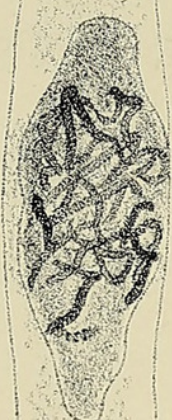

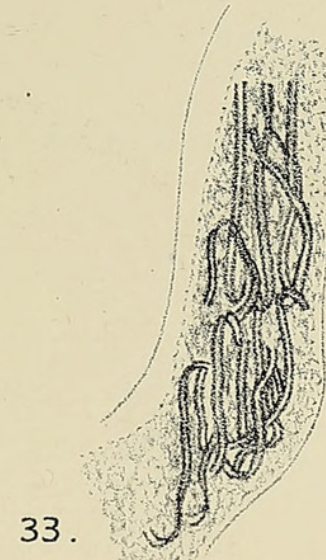

Divisions of Lilium Martaģon.

D

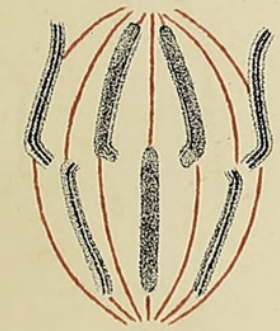

E

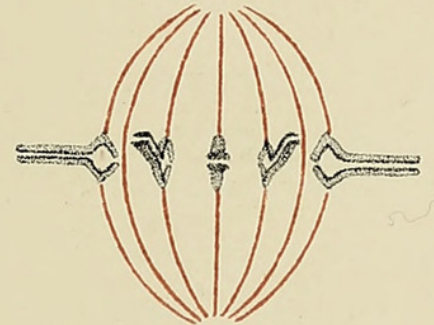

F

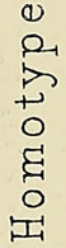

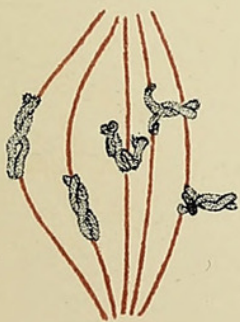

Early Spindle.

Nuclear Plate
27.
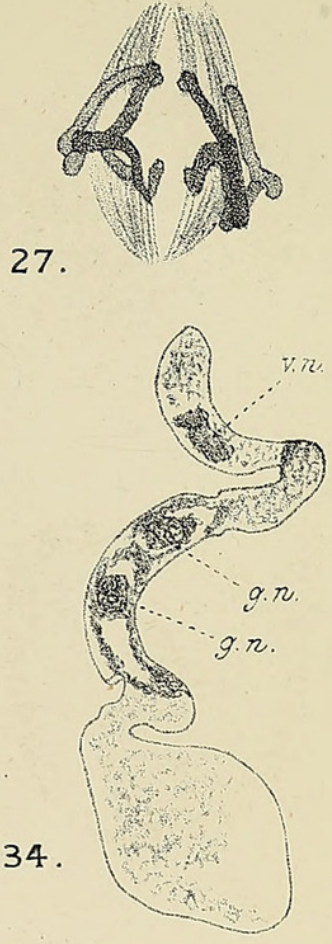

K

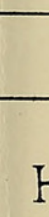

Early Spindle.

\begin{tabular}{|c|c|c|}
\hline$=(()$ & F & 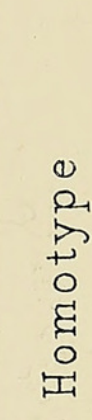 \\
\hline Nuclear Plate. & Diaster. & \\
\hline$\left((\sqrt{ })^{\mathrm{L}}\right.$ & $\mathrm{M}$ & 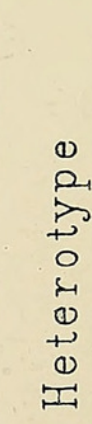 \\
\hline Nuclear Plate & Diaster. & \\
\hline
\end{tabular}




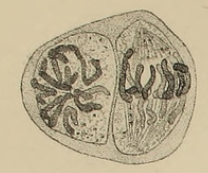

20.

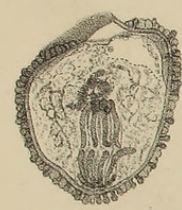

28.

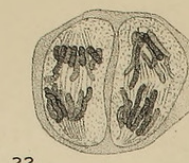

22.

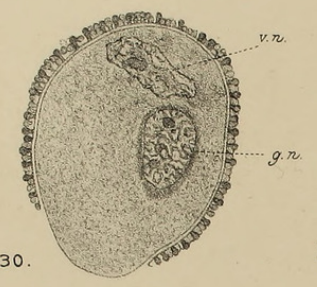

24.

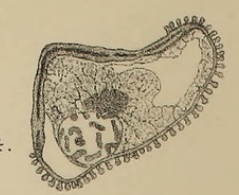

29.

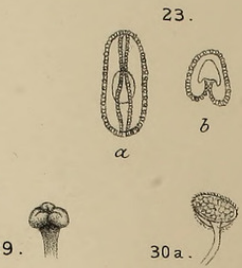

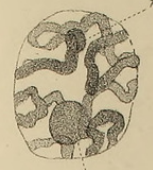

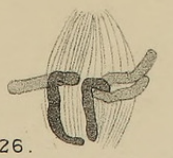

25. $n$
27.
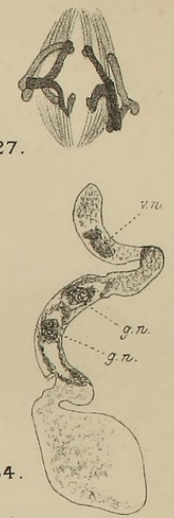

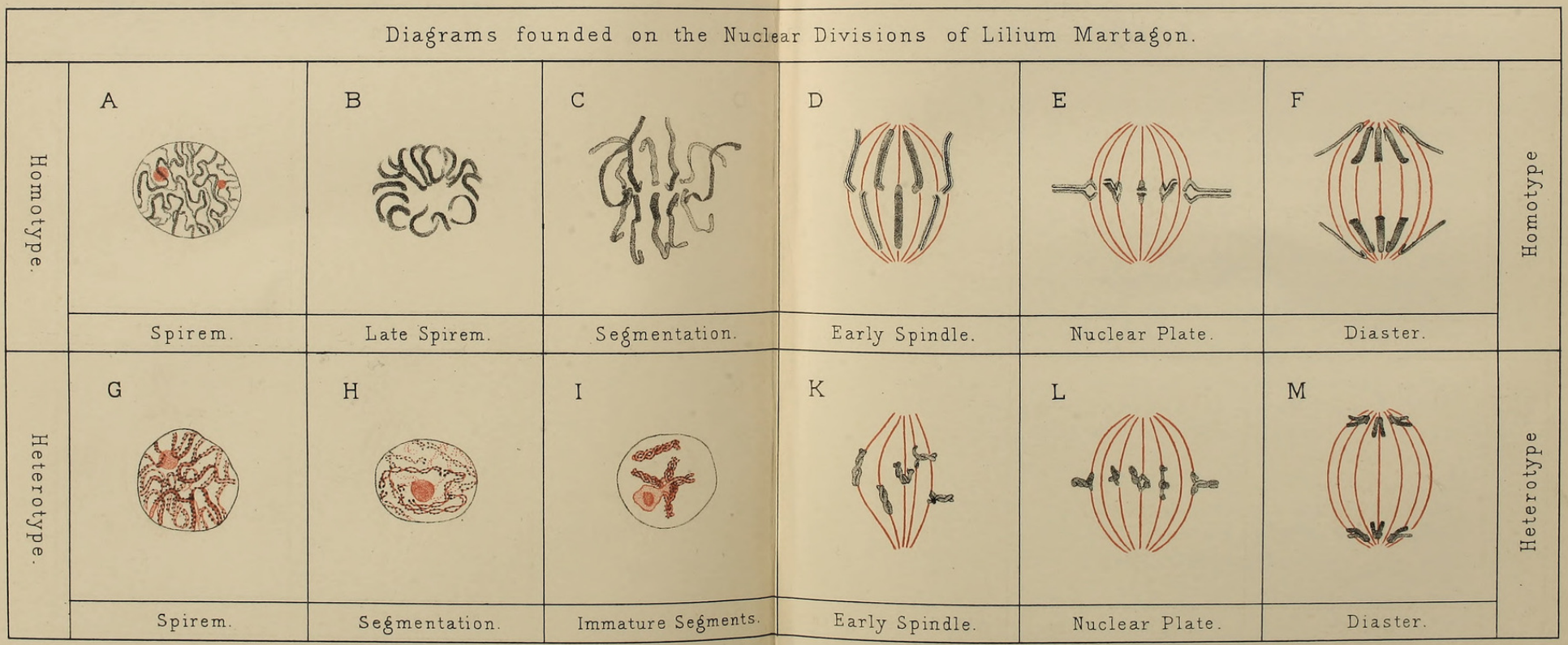

E Sargant del. 


\section{$2 \mathrm{BHL}$ Biodiversity Heritage Library}

Sargant, Ethel. 1897. "The formation of the sexual nuclei in Lilium martagon: II. spermatogenesis." Annals of botany 11, 187-224. https://doi.org/10.1093/oxfordjournals.aob.a088649.

View This Item Online: https://www.biodiversitylibrary.org/item/233542

DOI: https://doi.org/10.1093/oxfordjournals.aob.a088649

Permalink: https://www.biodiversitylibrary.org/partpdf/318461

\section{Holding Institution}

Smithsonian Libraries

\section{Sponsored by}

Biodiversity Heritage Library

\section{Copyright \& Reuse}

Copyright Status: Not in copyright. The BHL knows of no copyright restrictions on this item.

This document was created from content at the Biodiversity Heritage Library, the world's largest open access digital library for biodiversity literature and archives. Visit BHL at https://www.biodiversitylibrary.org. 